\title{
Improved sea level record over the satellite altimetry era (1993-2010) from the Climate Change Initiative project
}

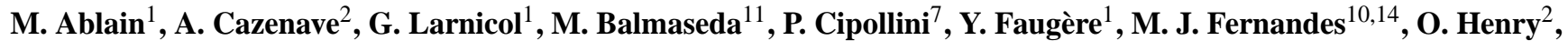 \\ J. A. Johannessen ${ }^{3}$, P. Knudsen ${ }^{6}$, O. Andersen ${ }^{6}$, J. Legeais ${ }^{1}$, B. Meyssignac ${ }^{2}$, N. Picot ${ }^{12}$, M. Roca ${ }^{8}$, S. Rudenko ${ }^{9}$, \\ M. G. Scharffenberg ${ }^{4}$, D. Stammer ${ }^{4}$, G. Timms ${ }^{5}$, and J. Benveniste ${ }^{13}$ \\ ${ }^{1}$ Collecte Localisation Satellite (CLS), Ramonville Saint-Agne, France \\ ${ }^{2}$ Laboratoire d'Etudes en Géophysique et Océanographie Spatiales (LEGOS), Toulouse, France \\ ${ }^{3}$ Nansen Environmental and Remote Sensing Center (NERSC), Bergen, Norway \\ ${ }^{4}$ University of Hamburg, Hamburg, Germany \\ ${ }^{5}$ CGI, London, UK \\ ${ }^{6}$ Technical University of Denmark (DTU), Lyngby, Denmark \\ ${ }^{7}$ National Oceanography Centre (NOC), Southampton, UK \\ 8 isardSAT, Barcelona, Catalonia, Spain \\ ${ }^{9}$ Helmholtz Centre Potsdam GFZ German Research Centre for Geosciences, Telegrafenberg 14473 Potsdam, Germany \\ ${ }^{10}$ Faculdade de Ciências, Universidade do Porto, 4169-007 Porto, Portugal \\ ${ }^{11}$ European Centre for Medium-Range Weather Forecasts (ECMWF), Reading, UK \\ ${ }^{12}$ Centre National d'Etudes Spatiales (CNES), Toulouse, France \\ ${ }^{13}$ European Space Agency (ESA), ESRIN, Frascati, Italy \\ ${ }^{14}$ Centro Interdisciplinar de Investigação Marinha e Ambiental (CIIMAR/CIMAR), Universidade do Porto, \\ 4050-123 Porto, Portugal
}

Correspondence to: M. Ablain (mablain@cls.fr)

Received: 7 July 2014 - Published in Ocean Sci. Discuss.: 21 August 2014

Revised: 25 November 2014 - Accepted: 27 November 2014 - Published: 13 January 2015

\begin{abstract}
Sea level is one of the 50 Essential Climate Variables (ECVs) listed by the Global Climate Observing System (GCOS) in climate change monitoring. In the past two decades, sea level has been routinely measured from space using satellite altimetry techniques. In order to address a number of important scientific questions such as "Is sea level rise accelerating?", "Can we close the sea level budget?", "What are the causes of the regional and interannual variability?", "Can we already detect the anthropogenic forcing signature and separate it from the internal/natural climate variability?", and "What are the coastal impacts of sea level rise?", the accuracy of altimetry-based sea level records at global and regional scales needs to be significantly improved. For example, the global mean and regional sea level trend uncertainty should become better than 0.3 and $0.5 \mathrm{~mm}_{\text {year }}{ }^{-1}$, respectively (currently 0.6 and $1-2 \mathrm{~mm}_{\text {year }}{ }^{-1}$ ). Similarly, interannual global mean sea level variations (currently uncertain to $2-3 \mathrm{~mm}$ ) need to be monitored with better accu-
\end{abstract}

racy. In this paper, we present various data improvements achieved within the European Space Agency (ESA) Climate Change Initiative (ESA CCI) project on "Sea Level" during its first phase (2010-2013), using multi-mission satellite altimetry data over the 1993-2010 time span. In a first step, using a new processing system with dedicated algorithms and adapted data processing strategies, an improved set of sea level products has been produced. The main improvements include: reduction of orbit errors and wet/dry atmospheric correction errors, reduction of instrumental drifts and bias, intercalibration biases, intercalibration between missions and combination of the different sea level data sets, and an improvement of the reference mean sea surface. We also present preliminary independent validations of the SL_cci products, based on tide gauges comparison and a sea level budget closure approach, as well as comparisons with ocean reanalyses and climate model outputs. 


\section{Introduction}

Global warming as a result of anthropogenic greenhouse gas emissions has already shown several visible consequences, among them the increase of the earth's mean air temperature and ocean heat content, melting of glaciers, and loss of ice masses from glaciers and the Greenland and Antarctica ice sheets. Ocean warming and land ice melting in turn are causing sea level to rise, with potentially negative impacts in many low-lying regions of the world. The precise measurement of sea level changes as well as its different components, at global and regional scales, is an important issue for a number of reasons. It provides information on how the climate system and its components respond to global warming and on the relative contributions of anthropogenic forcing and natural/internal climate variability. This also allows validation of the climate models developed for projecting future changes, as the models are supposed to correctly reproduce present-day and recent-past changes. The Global Climate Observing System (GCOS) has recently defined a set of 50 climate variables (called Essential Climate Variables ECVs) that need to be precisely monitored on the long term in order to improve our understanding of the climate system, its functioning and its response to anthropogenic forcing, as well as to provide constraints for climate modelling (GCOS, 2011). In 2010, the European Space Agency (ESA) developed a new programme, the Climate Change Initiative (CCI), dedicated to reprocessing a set of 13 ECVs currently observed from space; among them, the satellite altimetry-based sea level ECV. The objective of the CCI sea level project (called SL_cci below) was to produce a consistent and precise sea level record covering the past two decades, based on the reprocessing of all satellite altimetry data available from all missions (including the ERS-1\&2 and Envisat missions, in addition to the TOPEX/Poseidon, Jason- $1 \& 2$ and Geosat Follow-on (GFO) missions). During the first phase of the project, which lasted 3 years from 2011 to 2013, satellite altimetry data from seven altimeter satellites were reprocessed by the SL_cci consortium. Improved satellite orbits have been computed for all satellites except TOPEX/Poseidon and GFO using up-to-date force models and an improved reference frame realization. Updated geophysical corrections adapted to each satellite mission have been implemented after being evaluated and selected. Other improvements concern the reduction of instrumental drifts and biases (in particular for the Envisat mission), a new calculation of the mean sea surface used as reference, the method used for geographical averaging of sea surface height data, and the reduction of systematic bias between missions. The main SL_cci products computed during phase 1 consist of: (1) a global mean sea level (GMSL) time series at monthly intervals between January 1993 and December 2010, and (2) a global gridded sea level time series (resolution $0.25^{\circ} \times 0.25^{\circ}$ ) at the same time interval.
This paper intends to provide a global overview of the main results obtained in the frame of the SL_cci project. We firstly describe the validation protocol (Sect. 2) that has been applied to evaluate and select the algorithms and corrections used (Sect. 3) to generate the SL_cci products (described in Sect. 4). Then, Sects. 5 and 6 are focused on the assessment and the error characterization.

\section{Definition of a formal validation protocol}

The altimetry data processing system used to compute sea level (or the sea surface height, SSH) integrates a number of components: the altimeter range measurement (Range), the satellite orbit height (Orbit), and the instrumental and geophysical corrections. The estimation of these components needs additional information coming from different domains as orbitography (a force model) for the precise orbit determination, geodesy (geoid, mean sea surface, global isostatic adjustment (GIA), etc.), atmosphere (pressure, wind, dry and wet troposphere, etc.), and ocean (ocean tides, sea state, etc.). This information may be eventually linked together either directly or indirectly. Because of these complex interactions, sea level estimates (i.e. $\mathrm{SSH}=$ Orbit Range $\sum_{i=0}^{N}$ Correction $_{i}$ ) are provided with different standards. In practice, an optimized sea level calculation requires a large number of algorithms and corrections that need to be rigorously validated and regularly updated.

In the framework of the SL_cci project, we developed a new formal validation protocol which allowed us to evaluate the impact of new altimeter corrections or standards on a sea level record of climate quality, i.e. precise enough for climate studies. It consists in comparing the new altimeter corrections with corrections designed as a reference through their impact on the sea level calculation. This was done using a common set of validation diagnoses defined in such a way that they fulfil the sea level accuracy and precision requirements. The validation diagnoses are distributed into three distinct families allowing the assessment of altimetry data with complementary objectives:

1. the "global internal analyses" with the aim of checking the internal consistency of a specific mission-related altimetry system by analysing the computed sea level, its instrumental parameters (from altimeter and radiometer) and associated geophysical corrections,

2. the "global multi-mission comparisons" allowing evaluation of the coherence between two different altimetry systems through comparison of SSH data,

3. the "altimetry in situ data comparison" dedicated to the computation of the sea level differences between altimeter data and in situ sea level measurements, e.g. from 
tide gauges or Argo-based steric sea level data (Valladeau et al., 2012); this 3rd approach allows for the detection of potential drifts or jumps in the long-term sea level time series.

For each family, several validation diagnoses have been defined using elementary statistical approaches (e.g. mean, standard deviation, linear regression) and data representation (e.g. global mean time series, maps, histograms, periodograms). Other tests based on altimeter correction differences, sea surface height differences at satellite track crossovers, sea level anomalies, etc. were also performed. The list of all the diagnoses and their specification is described in detail in the Product Validation Plan (PVP) report of the SL_cci project for all referenced SL_cci reports available on the SL_cci website).

The analyses of these diagnoses were performed for different spatial (global mean and regional sea level, mesoscale) and temporal scales (Fig. 1, left panel): long-term > 10 years; interannual, 2-5 years; and periodic signals (annual, semiannual) scales. These spatio-temporal scales were chosen according to the sea level user requirements document (SL_cci User Requirements Document, 2014) presented below. This formal validation protocol allows us to determine, for each spatial and temporal scale, the level of impact (i.e. low or strong) of the new altimetry corrections on the sea level calculation (Fig. 1, right panel). For instance, if a new altimetry correction causes a GMSL trend $>0.15 \mathrm{~mm}$ year $^{-1}$ (over a period $>10$ years), we consider that the impact is strong, whereas if the trend effect is in the range 0.05$0.15 \mathrm{~mm}$ year $^{-1}$, it is assumed low, and negligible below $0.05 \mathrm{~mm}$ year $^{-1}$.

Our goal is also to check whether the new altimeter corrections improved or degraded the sea level estimates for each timescale. Most of the time, it was possible to clearly detect either improvement or degradation (illustrated Fig. 1, left panel, with the symbols "+" and "_" meaning improvement and degradation). For example, increased consistency between GMSL trends derived from two different altimetry missions or from in situ measurements demonstrates that the accuracy/precision of sea level data has been improved. In only a few cases were the diagnoses inconclusive. This occurred when errors of altimetry missions were of the same order of magnitude or correlated (e.g. same error for the regional mean sea level trends). In these rare cases, thorough investigations could be conducted through a "case by case" approach. When no obvious conclusion could be reached, the sea level differences due to the new correction were then allocated to the altimetry error budget (see Sect. 6).

Thanks to this formal validation protocol, the impact of all altimeter corrections could be described through a homogeneous approach and is therefore comparable between corrections. The table presented in Fig. 1 (left panel) allows us to provide easily and quickly relevant information about the impact of each correction on the sea level products.

\section{Development, validation and selection of new altimeter corrections and algorithms}

In this section, we present applications of the formal validation protocol described in Sect. 2. An important output of the SL_cci project was the development of new altimetry corrections (mentioned in Sect. 2) and algorithms (e.g. for merging data from different altimetry missions). A total of 42 new corrections/algorithms were evaluated within the project using the validation protocol described above. The reference standards were those used for AVIS0 products (Dibarboure et al., 2011) at the beginning of the SL_cci project. In order to select the best corrections, a "selection meeting" in Toulouse in May 2012 gathered a team of international experts in satellite altimetry, not involved in the SL_cci project. The new corrections were then selected on the condition that they led to improvements in sea level calculation. In the rare cases where the new processing did not improve the results or, even worse, led to deterioration, a conservative approach was applied and finally, the former corrections were unchanged. Table 1 presents the new selected corrections for each component and altimetry missions (for detailed information, see all the "SL_cci Validation Reports"). One of the most dramatic improvements comes from the use of ERA-interim reanalyses (from the European Centre for Medium-Range Weather Forecasts - ECMWF; Dee et al., 2011) instead of operational ECMWF fields to calculate the dry tropospheric and other dynamical atmospheric corrections. Applying our validation protocol, we noted strong improvements at mesoscale and regional spatial scales, over the first altimetry decade (19932003) (Carrere et al., 2014; "SL_cci Validation reports, Atmospheric corrections", 2014). The GMSL error reduction (Fig. 2, top) obtained from crossover analyses is of the order of $2.5 \mathrm{~cm}$ on the early years of the altimetry era (1993-1995). Then, the error decreases linearly until 2004, and remains stable close to 0 during recent years. The improvement observed in the first decade (1993-2003) is stronger at high latitudes $(6 \mathrm{~cm})$ where the atmospheric pressure and wind fields have strong high-frequency variability. Looking at regional sea level trends (Fig. 2), significant trend differences are observed $\left(>1 \mathrm{~mm}_{\text {year }}{ }^{-1}\right)$ mainly in the South Pacific Ocean below $50^{\circ} \mathrm{S}$ latitude.

Similarly, the model-based wet tropospheric correction was also strongly improved (until $1 \mathrm{~cm}$ error reduction on the GMSL) before 2002 using ERA-interim instead of ECMWF operational fields (Legeais et al., 2014). While not as good as the wet troposphere corrections derived from the on-board microwave radiometers (MWRs), the ERA-Interim wet tropospheric correction allows us to better characterize the uncertainty of wet troposphere content over the long term (Thao et al., 2014; Legeais et al., 2014). However, this was not used in the sea level calculation, where the radiometer-based corrections were preferred.

In parallel, the radiometer-based corrections have been improved using combined estimates from valid on-board MWR 


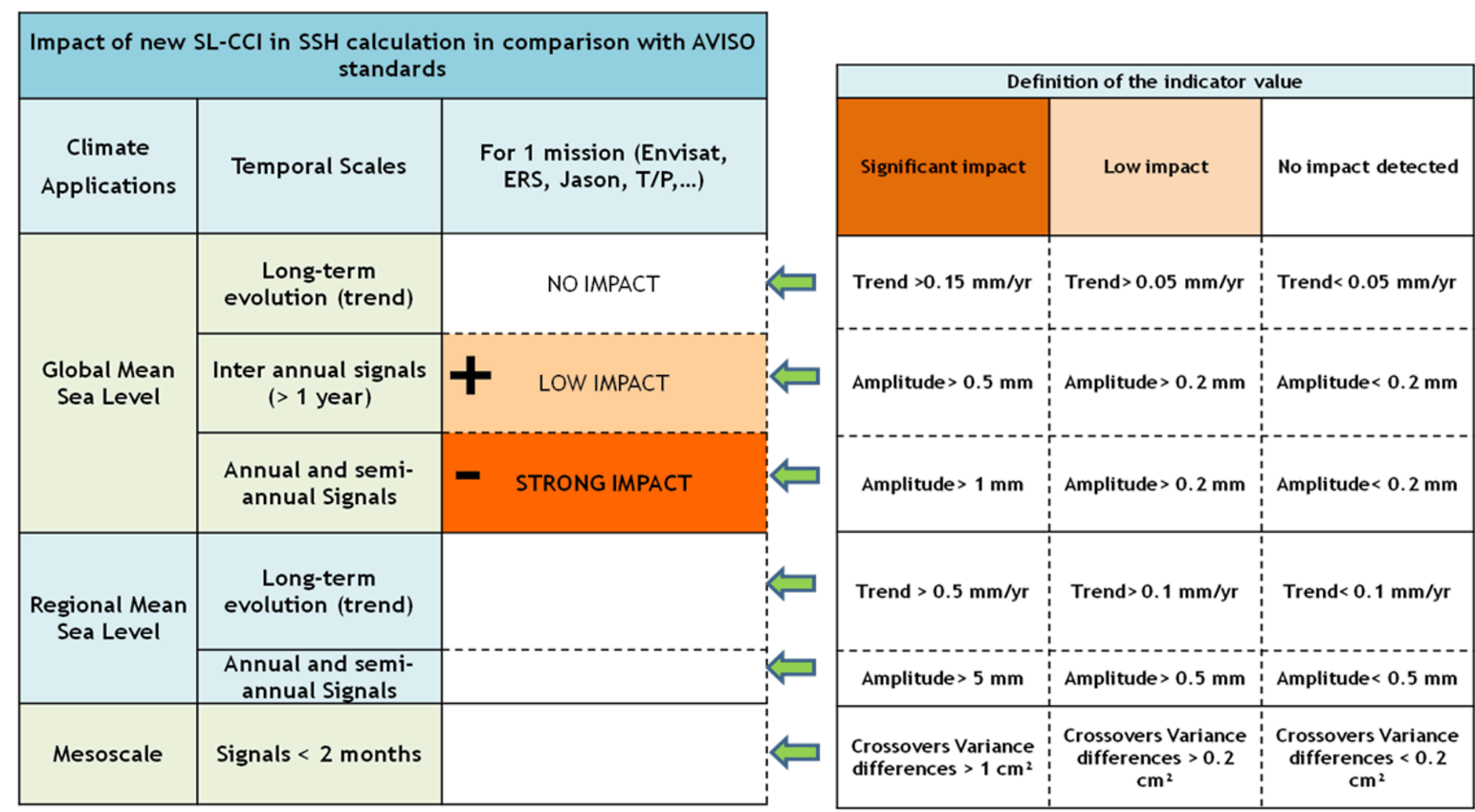

Figure 1. Definition of the temporal and spatial scales (left panel) and the indicator value table (right panel) allowing the impact characterization in sea level of new SL_cci corrections in comparison with corrections defined as reference (AVISO-2010).

Table 1. New corrections selected for the sea level calculation for the SL_cci project. The unfilled boxes indicate that the AVISO standards (release 2010) have been applied.

\begin{tabular}{l|c|c|c|c}
\hline Corrections & ERS-1 $\mid$ ERS-2 & Envisat & Jason-1 & Jason-2 \\
\hline Orbit & $\begin{array}{l}\text { Reaper combined orbit } \\
\text { (Rudenko et al., 2012) }\end{array}$ & $\begin{array}{c}\text { GDR-D CNES } \\
\text { (Couhert et al., 2015) }\end{array}$ \\
\hline Instrumental correction & $\mid$ & $\begin{array}{l}\text { New PTR correction (Garcia and } \\
\text { Roca, 2010) }\end{array}$ & $\mid$ GFO \\
\hline Sea state bias & $\mid$ V2.1 release & $\mid$ GDR-D release $\mid$ \\
\hline Wet troposphere & $\mid$ & GPD corrections (Fernandes et al., 2010, 2014) \\
\hline Dry troposphere & ERA-interim based (Carrere et al., 2014) \\
\hline Dynamical atmospherical corrections & $\mid$ & ERA-interim based (Carrere et al., 2014) \\
\hline Ocean tide & GOT 4.8 (Ray et al., 2013) \\
\hline Mean sea surface & DTU 2010 (Andersen et al., 2010)
\end{tabular}

values, global navigation satellite systems (GNSS) measurements and ECMWF model (ERA Interim fields) in areas where the MWR measurements are degraded due to, for example, land or ice contamination or instrument malfunction (Fernandes et al., 2010, 2014). This new correction, called GNSS-derived path delay (GPD), computed for all ESA and reference missions, brings improvements mainly in coastal areas and in the polar regions. In Fig. 3, the sea level error reduction is plotted vs. the distance to the coast using the new GPD corrections instead of the reference radiometerbased corrections. For almost all missions, except Jason-2, which already benefits from an improved coastal radiometer correction (Brown et al., 2009), there is a significant SSH error reduction, close to $1 \mathrm{~cm}$ between 20 and $40-50 \mathrm{~km}$ from the coast. Improvements have also been noticed in the open ocean, especially for TOPEX data (Fernandes et al., 2014), where radiometer data gaps degrade the interpolation process. Finally, the GPD corrections have been selected for all altimeter missions because of the noted improvement in the sea level calculation at short and long timescales, mainly in coastal and polar regions.

Orbit error is the main source of the error for the longterm sea level evolution at oceanic basin scales (Couhert et al., 2015). Strong efforts have been made within the 

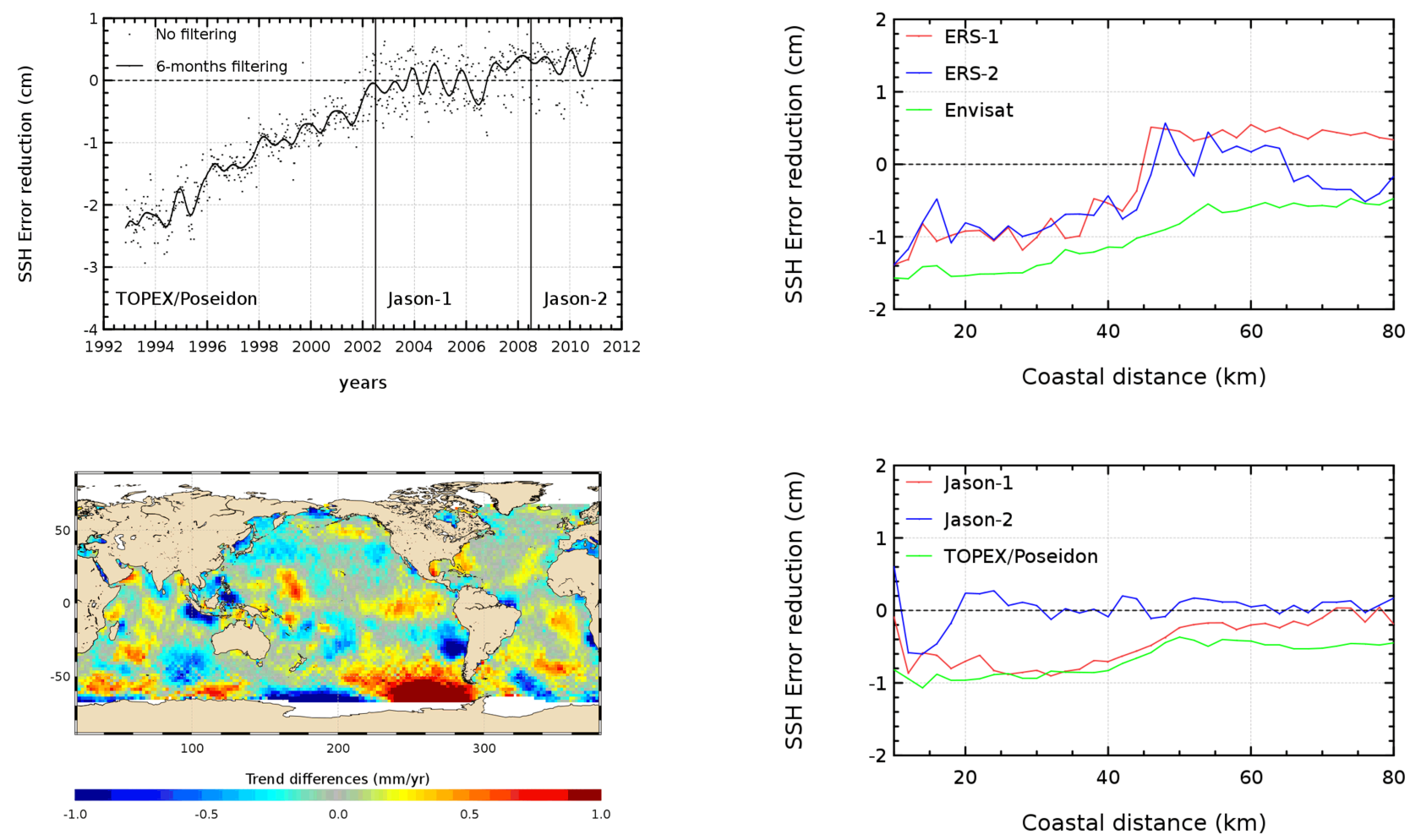

Figure 2. Evolution of the sea level error reduction applying the new dynamical atmospheric and dry troposphere corrections derived from ERA-Interim reanalyses instead of operational ECMWF fields (top) and impact on sea level regional trends (bottom).

SL_cci project to develop new orbit solutions (Rudenko et al., 2014) and to compare them with external solutions provided by other projects. The International Terrestrial Reference Frame (ITRF) realization (Altamimi et al., 2011) and the earth gravity field model used in the orbit computation are crucial as far as the quality of orbit solutions is concerned. After analysing all orbit solutions for all the missions, the REAPER combined orbit solutions (Rudenko et al., 2012) have been selected for ERS-1 and ERS-2, with the new CNES GDR-D orbit solutions (Couhert et al., 2015) being selected for the Jason-1, Jason-2 and Envisat missions. Strong effects were observed on the regional sea level trend, in the range of $1-2 \mathrm{~mm}_{\text {year }}{ }^{-1}$, with large patterns at hemispheric scale when using static and time-variable earth gravity field models for orbit computation (Fig. 4). Thanks to cross-comparisons between altimetry missions (Ollivier et al., 2012) and with in situ measurements (Valladeau et al., 2012), we have demonstrated that these new orbit solutions dramatically improved the regional sea level trends. Furthermore, this inter-comparison, using different orbit solutions, provided interesting information on the orbit sensitivity to the choice of the earth gravity field model (Rudenko et al., 2014).

In addition to these major improvements, other corrections were also selected, although their impact on the sea

level estimate was lower. These concern the ionospheric correction with the use of the NIC09 (New Ionosphere Climatology) model for ERS-1 (Scharroo and Smith, 2010), the GOT4.8 (Geocentric Ocean Tide) ocean tide solution (Ray et al., 2013), and the DTU10 (Danish Technical University) mean sea surface (Andersen et al., 2010) for all missions. In addition, we benefited from the reprocessing of Envisat and Jason-2 level-2 products "GDR V2.1" (Ollivier et al., 2012) and "GDR-D" (Philipps and Roinard, 2013). This allowed us to increase the data coverage (mainly for Envisat) and to improve the sea-state bias corrections along with instrumental bias and drift corrections. For the latter, the impact is strong for Envisat since a global instrumental drift of about 2 mm year $^{-1}$ was identified and corrected in the altimeter range (Thibaut et al., 2010; Roca and Thibaut, 2009; Garcia and Roca, 2010). It is worth mentioning that the SL_cci project contributed to correcting this anomaly, while Envisat was designed not for climate studies but rather for mesoscale variability.

The last new algorithm developed and selected aims at better combining the different sea level time series from TOPEX, Jason-1, and Jason-2 at regional scale. Thanks to the verification phase between these missions, systematic geographical biases could be detected. These biases are mainly latitude-dependent, with variations close to $0.5 \mathrm{~cm}$ between 

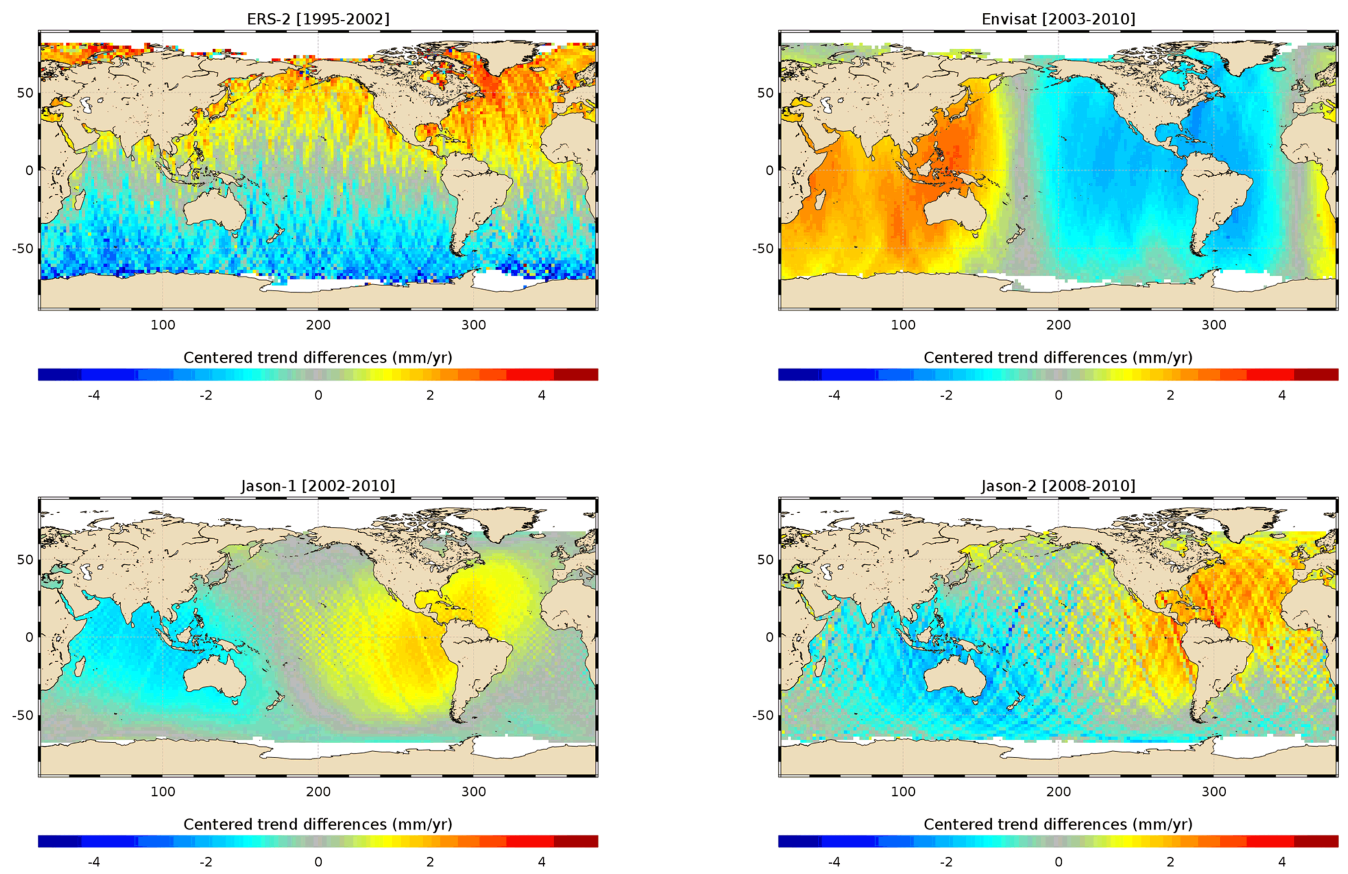

Figure 4. Impact of the new orbit solutions on the regional sea level trends for ERS-2 (Reaper combined vs. DEOS DGM-E04 orbit solutions), Envisat, Jason-1, and Jason-2 (CNES GDR-D vs. CNES GDR-C orbit solutions).

Jason-1 and Jason-2, and $1 \mathrm{~cm}$ between TOPEX and Jason1. Correcting these regional and systematic sea level differences (see the SL_cci Validation Report, Regional SSH bias corrections between altimetry missions, 2014), led us to better combine these three altimetry missions and therefore better estimate the long-term sea level evolution at regional scales. The impact of these corrections on regional MSL trends plotted in Fig. 5 from 1993 to 2010 is close to $\pm 0.3 \mathrm{~mm}$ year $^{-1}$, with large hemispheric dependence.

\section{New CCI-based sea level records}

Sea level products were generated using the new altimeter corrections described in Sect. 3. The same procedure was adopted as for the SSALTO DUACS (Segment Sol Multimission Altimetrie et Orbitographie, Data Unification and Altimeter Combination System; Dibarboure et al., 2011). After calculating the along-track sea level for each of the seven missions (TOPEX/Poseidon, Jason-1, Jason-2, ERS-1, ERS2, Envisat, and Geosat Follow-on) over the [1993, 2010] period, the main steps consisted of: combining all missions together, reducing the orbit and the long wavelength errors, computing the gridded sea level anomalies using an objective analysis approach (Ducet et al., 2000; Le Traon et al., 2003), and generating mean sea level products (e.g. GMSL time series, gridded sea level time series) dedicated for climate studies. The SL_cci products are monthly grids time series with a spatial resolution of $0.25^{\circ}$ using a rectangular projection. The GMSL time series (also at monthly interval) is based on the geographical averaging over the oceanic domain observed by the altimetry data $\left(82^{\circ} \mathrm{S}\right.$ to $\left.82^{\circ} \mathrm{N}\right)$ of the gridded data. Additional products (called indicators) are provided: GMSL trend, regional MSL trends, amplitudes and phases of the main periodic signals (annual, semi-annual), etc.

Access to the SL_cci products can be obtained by sending an email to: info-sealevel@esa-sealevel-cci.org. The Product User Guide (PUG, 2013) and Product Specification Document (PSD, 2013) provide further details.

Comparisons between the SL_cci product and the AVISO2010 products (Dibarboure et al., 2011) were performed by applying the formal validation protocol described above (Sect. 2). Concerning the GMSL trend, similar values were obtained for both time series: $3.2 \mathrm{~mm}$ year $^{-1}$ over the 1993 2010 time span. At the interannual timescale (highlighted by calculating the difference between the two GMSL time series (Fig. 6, top panel), small differences in the range 1-2 $\mathrm{mm}$ or lower are noticed, except for 1994 where a $4 \mathrm{~mm}$ jump is observed. This jump is due to an anomalous value of the AVISO-2010 products caused by an inadequate merging of the TOPEX data with the ERS-1 data of the non-repetitive geodetic phase (Pujol et al., 2014). The most impressive result is obtained by separating the ERS-1/ERS-2/Envisat and TOPEX/Jason-1/Jason-2 global GMSL time series using alternately the old and new altimeter corrections (Fig. 7): the trend difference between the two time series is now close to $0.6 \mathrm{~mm} \mathrm{year}^{-1}$ from 1993 to 2010 instead of about $1.5 \mathrm{~mm}$ year $^{-1}$ previously. This improved consistency does 


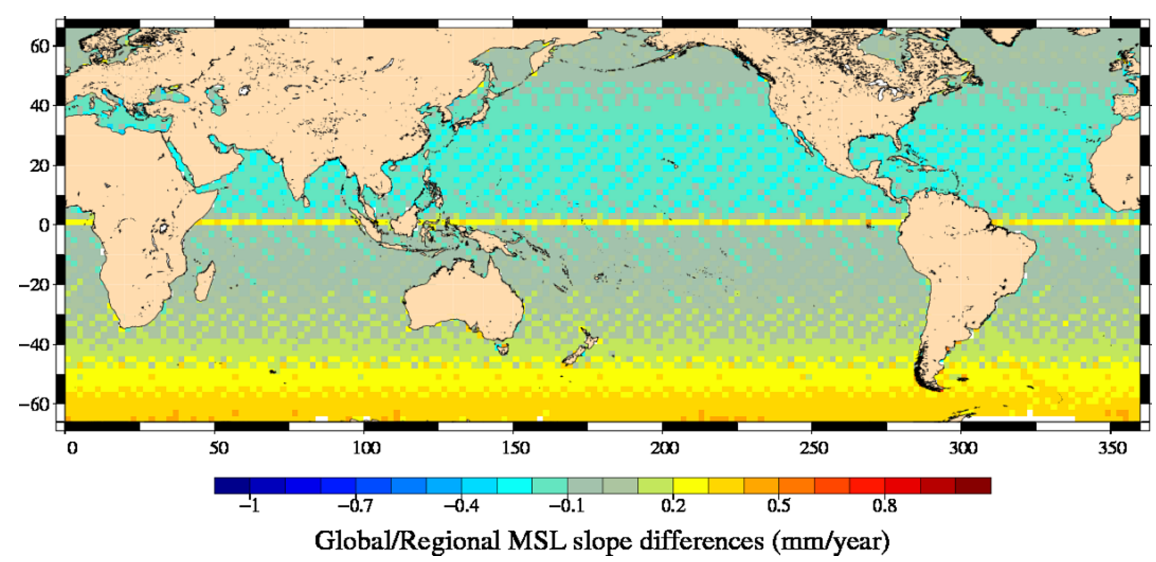

Figure 5. MSL trend differences from 1993 to 2010 between sea level maps without and with regional bias corrections for TOPEX/Jason-1 and Jason-1/Jason-2.

not have a direct impact on the GMSL trend, which depends only on the TOPEX/Jason-1/Jason-2 missions. However, this provides increased confidence in the long-term GMSL time series.

Looking at the regional sea level trend differences (Fig. 6, bottom panel), large geographically correlated structures are observed. Their amplitude is in the $\pm 2 \mathrm{~mm} y e a r^{-1}$ range. They primarily result from the new orbit solutions (hemispheric effects), the new ERA-interim atmospheric fields (at high latitudes), the new wet tropospheric correction, and the geographical biases arising when linking altimetry missions together. Comparing with in situ measurements (tide gauges and Argo-based steric sea level) indicates a better consistency at the regional scale with the new SL_cci data (see SL_cci Product Validation Internal Report - PVIR, 2014). It is more difficult to detect any improvement at short spatial scales, because either the spatial or temporal sampling of in situ measurements is not good enough or because the error generated by the collocation method between the in situ and altimetry data is larger than the target signal (Couhert et al., 2015). We also examined the periodic (annual and semiannual) sea level signals. We found differences in the order of $5 \mathrm{~mm}$ on average for the amplitude of the annual signal. In some regions (the tropics), the differences can reach $1 \mathrm{~cm}$. While we think that the new seasonal signal is improved compared to the AVISO-2010 products, it is not possible to demonstrate this through any independent validation diagnoses. Indeed, comparisons with the in situ measurements are not accurate enough to observe such signals.

\section{Validation of the temporal and spatial variations of global sea level}

The SL_cci products delivered at the end of Phase 1 are currently under validation and evaluation. Two different approaches have been developed:
1. assessment of the accuracy of the SL_cci products through their use in ocean reanalyses and earth system models;

2. assessment of the global sea level budget.

In approach (1), the accuracy of the SL_cci data is evaluated by quantifying the model performances and robustness (compared to the use of a reference sea level data set, e.g. AVISO standard data) in representing a number of physical processes (e.g. the sea level drop associated with the $2011 \mathrm{La}$ Niña, the Indonesian through flow, changes in the Arctic circulation, effects of monsoon on sea level, regional sea level fingerprint due to wind stress, steric sea level trend patterns).

Approach (2) consists of comparing the SL_cci GMSL and variability to (i) other GMSLs, and (ii) the sum of the climatic and non-climatic components estimated independently (changes in thermal expansion, glacier and ice sheet mass balance, and land water storage).

\subsection{Assessment based on numerical ocean models}

Ocean model simulations are an effective way of translating wind and heat fluxes information into sea level variations, thus providing independent verification of their contribution to sea level. Sea level from ocean-only simulations at different resolutions $\left(1^{\circ}, 0.25^{\circ}\right)$ has been contrasted with alongtrack data and with gridded (filtered and merged) sea level maps from AVISO (Dibarboure et al., 2011) and SL_cci. The statistics of the comparison (correlation, rms error, differences in trends) were similar when using AVISO and SL_cci data. Differences between models and any observed estimations were much larger than the differences between observational products. The spatial patterns of these differences were suggestive of model error. For instance, small-scale sea level variability is much larger in observed products than in models, which is consistent with insufficient resolution in the models. In contrast, the low-frequency and large-scale vari- 

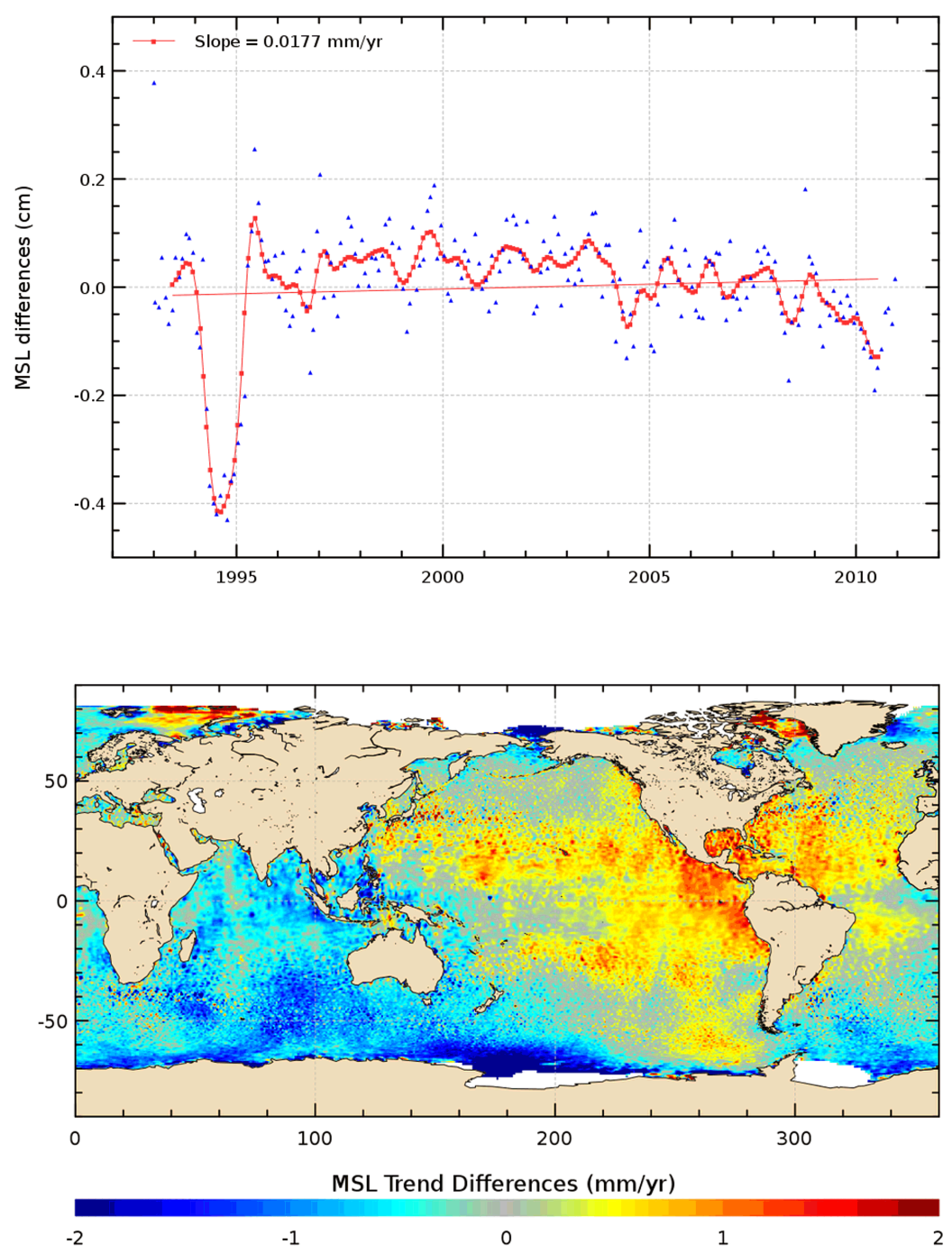

Figure 6. GMSL (top panel) and regional sea level (bottom panel) differences between the SL_cci (release 1.1) and AVISO products (release 2010).

ability is more obvious and better resolved in models. The large-scale patterns of interannual variability and trends are consistent between models and observations, but differences exist associated with the precise location of strong current systems, which models struggle to capture. This information is in itself interesting, and suggests that a large part of the sea level variability is of a dynamic nature, associated with changes in the wind-driven circulation. Both AVISO and SL_cci were useful to detect improvements in ocean model simulations due to the increased resolution.

In the Arctic Ocean the SL_cci reprocessed data reveal some distinct features of the elevated trend in sea level rise, notably in the Beaufort Sea, in the Norwegian Sea, in the Sub-Polar gyre, and in the northeast Atlantic south of the Iceland-Faroe ridge. The Beaufort Sea rise of about 6.5$7 \mathrm{~mm}$ year $^{-1}$ has also been reported by Morrison et al. (2011) and Laxon et al. (2012), while the elevated feature of around
6-7 mm year ${ }^{-1}$, as detected in the SL_cci field in the Lofoten Basin of the Norwegian Sea, compares rather well with the trend recovered from in situ hydrographic observations.

A first look at the three general circulation models (GCMs), NorESM (Norwegian Earth System Model), Hadley, and IPSL (Institut Pierre-Simon Laplace), reveals large individual differences in the trend of sea level change, regarding the overall trend as well as in its regional characteristic changes. The contributions to these simulated changes include the regional variability of the steric and the mass components, while there is no account of the GIA. In comparison to the SL_cci sea level change the NorESM simulations $\left(1^{\circ}\right.$ resolution) yield the best agreement in the SubPolar gyre, in the northeast Atlantic Ocean south of the Iceland-Faroe ridge, in the Lofoten basin of the Norwegian Sea and in the Beaufort Gyre. This inter-comparison of the SL_cci trends with the trends derived from the three GCMs 

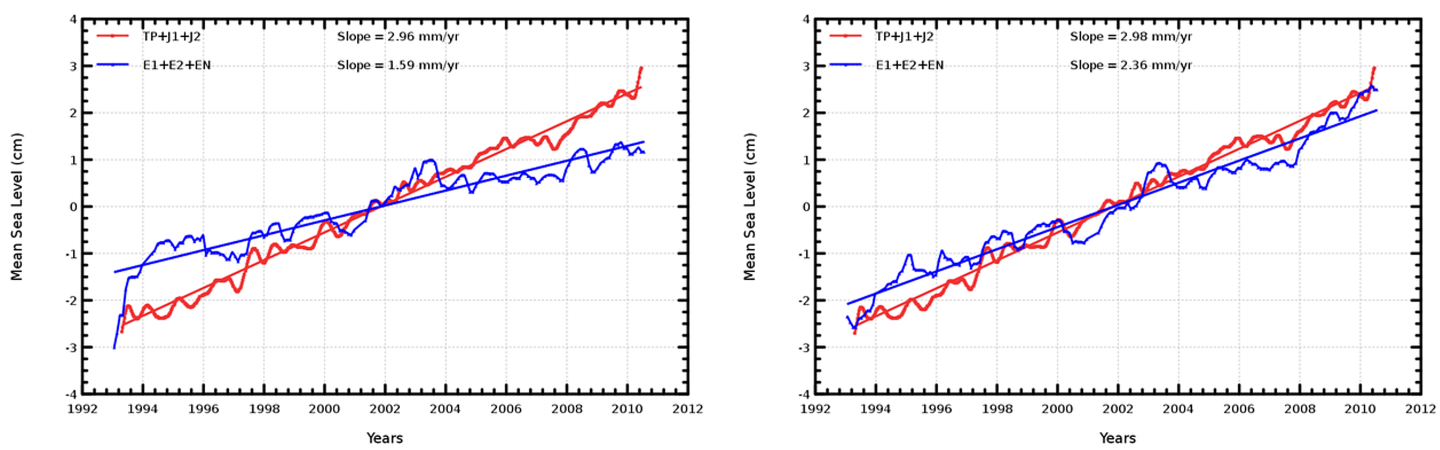

Figure 7. GMSL time series separating ERS-1/ERS-2/Envisat and TOPEX/Jason-1/Jason-2 altimeter missions using alternatively the old (AVISO-2010 standards) on left and new altimeter correction (SL_cci) on right.

can therefore provide evidence for how realistic the model simulations are with respect to the regional variability of the water masses (steric height contribution) and variability, spreading, and accumulation of freshwater discharges from melting ice sheets and glaciers (mass changes).

In summary, as was to be expected from the beginning, even ocean-only simulations are not able to identify the incremental improvement of SL_cci vs. its predecessor. Nevertheless, this validation exercise has shown that the SL_cci is a robust data set for ocean and climate models validation, and can discern verification metrics.

\subsection{Assessment based on ocean data assimilation}

Data assimilation methods can be very effective methods to test the quality of the input data. This approach was used here to evaluate the SL_cci products, either by direct assimilation of the product as an ocean synthesis (active mode) or by simple comparison with a reference state (passive mode), obtained by a forced ocean model combined with in situ observations, and even other sea level observations. In this way, the ocean synthesis, containing information from both the model forced with realistic atmospheric state and observations, should have less error than an ocean model simulation alone. The passive comparison can be done a posteriori (by comparing ocean reanalyses with SL_cci), or during the assimilation process, by contrasting, at the appropriate location and time, the along track altimeter data with the estimate given by an ocean model that assimilates in situ temperature and salinity.

In a first step, sea surface height fields available from the GECCO2 assimilation approach (Köhl, 2014) were compared to the AVISO products as well as to the SL_cci product. Of these two, the AVISO product was used to constrain the model, but not the SL_cci product. The comparison was performed to investigate whether the new SL_cci product is closer to the GECCO2 ocean reanalysis product, which is constrained by most of the available global data sets, than the previous AVISO data set, a test that would highlight a better consistency of the new SSH data with ocean dynamics and other ECV information. The comparisons have been performed separately for the ERS (ERS-1, ERS2 and ENVISAT) and the TOPEX/Poseidon satellite-series (TOPEX/Poseidon, Jason-1 and Jason-2). Figure 8 shows the ratio (RMS_AVISO/RMS_SL_cci) of the rms differences between the GECCO model and the satellite time series of ERS-1, ERS-2 and ENVISAT for AVISO (RMS_AVISO) and SL_cci (RMS_SL_cci) in percent improvement at model resolution. Red indicates improvements of the SL_cci compared to the AVISO data set and blue degradation. Remarkable are the improvements in the North Atlantic, in the Indian Ocean through flow and in many parts of the ocean. The regions where SL_cci shows less skill compared to AVISO are the ones where the GECCO2 solution has adapted very well to AVISO and at the same time where the standard deviation of the data sets are very small, indicating a small signal to noise ratio in these regions. Therefore, the model might have adapted to the not as good AVISO data and thus gives less skill in comparison to the improved SL_cci data set. The improved regions (red colours) cover $62.8 \%$ of the ocean area that had valid data for the comparison, leaving $37.2 \%$ of the ocean area that has degraded (blue colours). Further, when averaging the ratio of RMS_AVISO/RMS_SL_cci globally, weighted by the area of each grid point, a global mean improvement of $0.91 \%$ can be seen from the analysis on the model grid. This could demonstrate that the SL_cci has been improved in many regions.

Both AVISO and SL_cci sea levels have also been compared with the sea level from the ORAS4 ocean reanalyses (Balmaseda et al., 2013), which assimilate in situ temperature, salinity, and AVISO data along a track altimeter. Time series of standard area-averaged climate indices have been used to gain insight on the differences between the AVISO and SL_cci products. Figure 9 shows a time series of the 12 month running mean sea level anomaly differences. In the eastern Pacific $\left(5^{\circ} \mathrm{N}-5^{\circ} \mathrm{S}, 130-90^{\circ} \mathrm{W}\right.$, left panel) both ORAS4 and SL_cci show a positive offset with respect to AVISO data after 2005 (from 2005 onwards the ocean state in ORAS4 is relatively well constrained by Argo). In addi- 


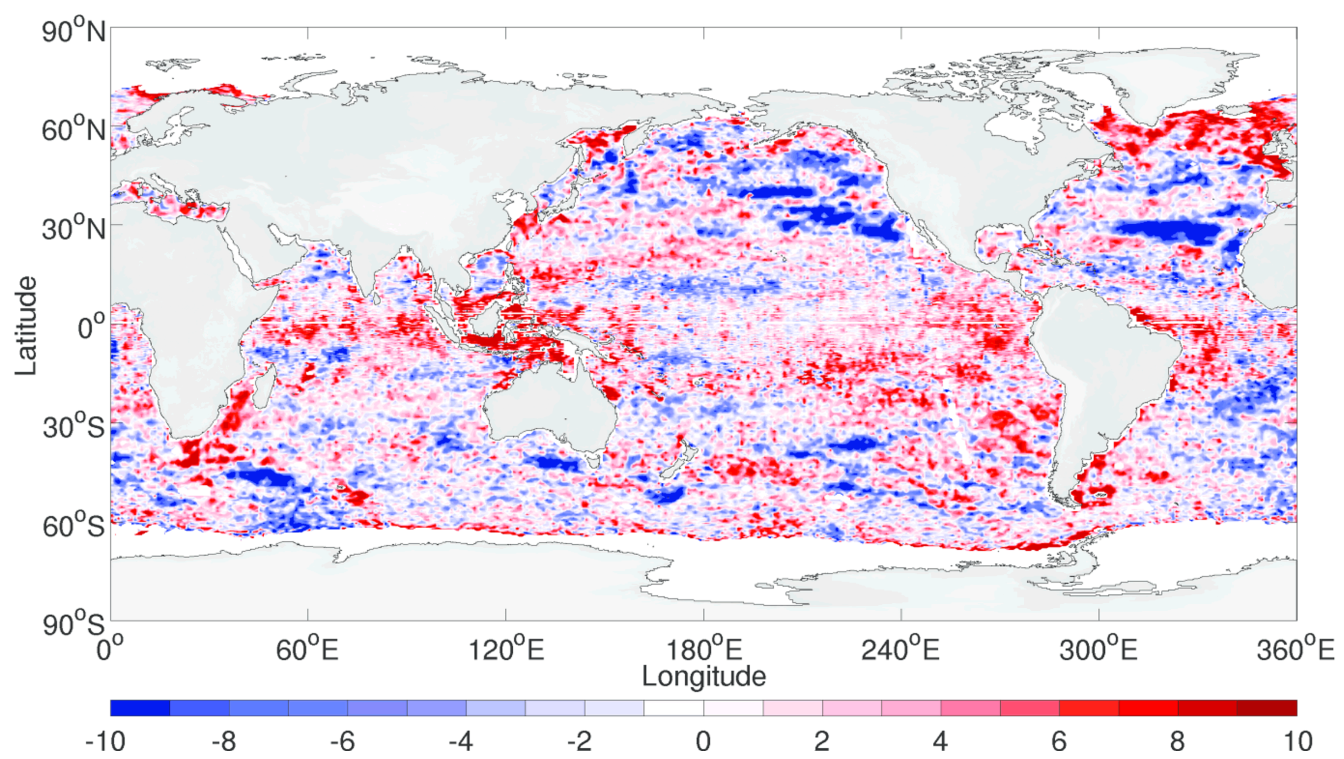

Figure 8. Ratio of the rms differences RMS_AVISO and RMS_SL_cci between the GECCO model and the satellite time series of ERS-1, ERS-2, and ENVISAT in percent improvement.

Sea Level differences respect to AVISO

Eastern Equatorial Pacific

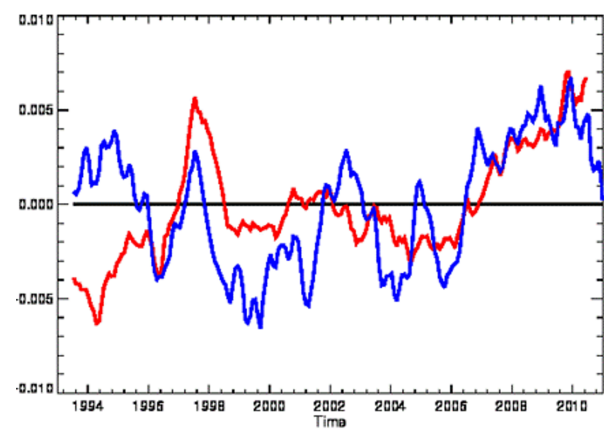

Southern Indian Ocean

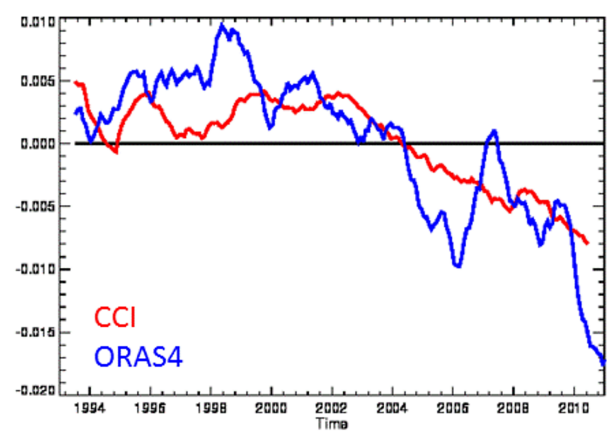

Figure 9. Differences $(\mathrm{m})$ in the sea level time evolution (12 month running mean) with respect to the AVISO product of SL_cci (red) and ORAS4 (blue) . Left: eastern equatorial Pacific $\left(5^{\circ} \mathrm{N}-5^{\circ} \mathrm{S}, 130-90^{\circ} \mathrm{W}\right)$. Right: southern Indian Ocean $\left(30-70^{\circ} \mathrm{S}, 20-150^{\circ} \mathrm{E}\right)$. The differences in trends between SL_cci and AVISO are confirmed by ORAS4. In the eastern Pacific, both ORAS4 and SL_cci have a stronger El Niño-Southern Oscillation signature than AVISO.

tion, SL_cci and ORAS4 data consistently show stronger local maxima associated with El Niño, 1997. The precursor of this El Niño is visible in the western Pacific slightly earlier, and it is also more pronounced in SL_cci and ORAS4 than in AVISO (not shown). The right panel of Fig. 9 shows the equivalent time series for the southern Indian Ocean (30$70^{\circ} \mathrm{S}, 20-150^{\circ} \mathrm{E}$ ), where both ORAS4 and SL_cci consistently show a negative tendency with respect to AVISO, suggesting that AVISO overestimates the sea level rise in this area. The differences in trends between SL_cci and AVISO shown in these time series are similar to those shown in Fig. 6 (bottom). The variability of the ORAS4 reanalysis agrees better with the SL_cci product than with AVISO.

\subsection{Comparison of the SL_cci GMSL time series with other GMSL products}

We constructed a GMSL time series by geographically averaging the SL_cci gridded data between $66^{\circ} \mathrm{S}$ and $66^{\circ} \mathrm{N}$. A simple cosine of latitude weighting was applied to the data. As no glacial isostatic adjustment (GIA) correction was applied to the gridded data, we added the usual $+0.3 \mathrm{~mm}$ year $^{-1}$ GIA trend from the SL_cci GMSL (as usually done by other processing groups). We further compared the SL_cci GMSL with altimetry-based GMSL time series computed by different processing groups (AVISO, University of Colorado (CU), NOAA (National Oceanic and Atmospheric Administration), GSFC (Goddard Space Flight Cen- 

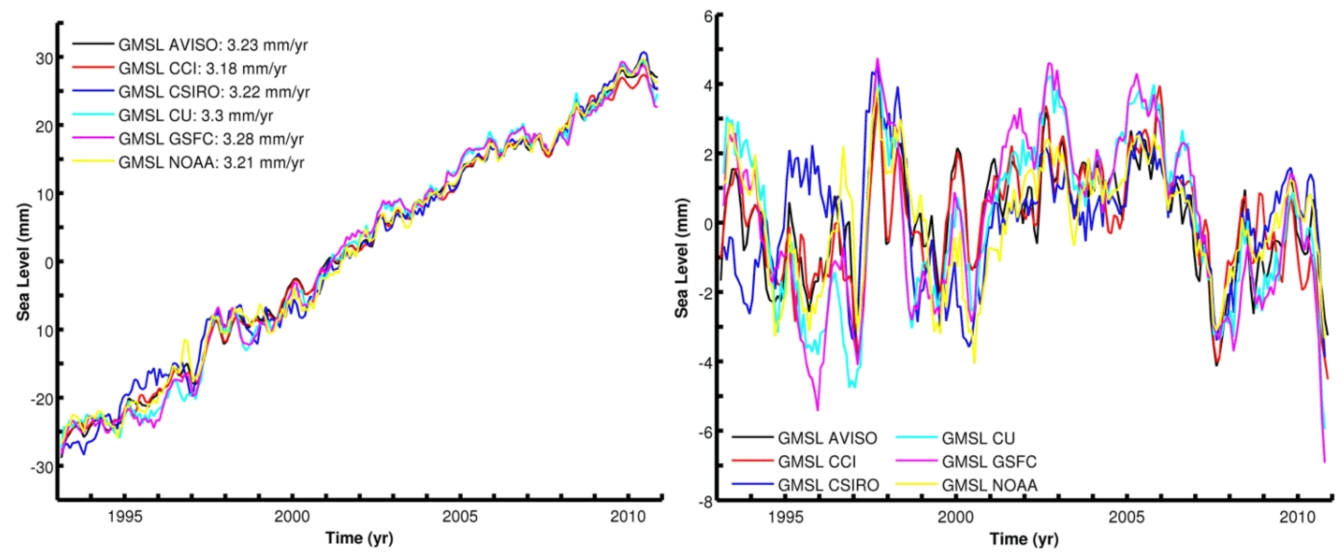

Figure 10. GMSL based on multi-mission satellite altimetry data processed by different groups (including SL_cci project). Left/right panel: with/without the global mean trend.

ter), and CSIRO (Australia's Commonwealth Scientific and Industrial Research Organisation). The results are shown in Fig. 10 (left panel). In terms of trends, all curves are very similar to each other and trend differences $\left(<0.2 \mathrm{~mm}\right.$ year $\left.^{-1}\right)$ are fully covered by the formal error on the trend computation. However, it is interesting to note that all sea level curves differ significantly (by several $\mathrm{mm}$ ) over an interannual timescale. This is illustrated in Fig. 10 (right panel), and is particularly noticeable during the TOPEX/Poseidon period (1993-2001), with a significant big departure of the CSIRO GMSL from other curves. The detrended SL_cci GMSL is in general close to the AVISO GMSL, although slight differences are noticed at the end of the study period.

\subsection{Comparison of the SL_cci GMSL with steric and ocean mass components (sea level closure budget); interannual time scale}

GMSL change is a combination of ocean mass and steric (thermal expansion) changes. We compared the GMSL computed from the SL_cci gridded product with the sum of steric and mass components over the Argo and GRACE (Gravity Recovery and Climate Experiment) operating period (since $\sim 2005$ ). Argo-based steric data used for this comparison are based on those processed by Karina von Schuckmann (von Schuckmann and Le Traon, 2011). Ocean mass has been estimated using the RL05 data from the GRACE project (average of the three products: CSR, JPL and GFZ; Chambers and Bonin, 2012). The GRACE and steric data have been averaged over the $66^{\circ} \mathrm{S}$ and $66^{\circ} \mathrm{N}$ domain. Figure 11 compares three GMSL products (AVISO, CU, and SL_cci) with the sum of steric and mass contributions over 2005-2010. Error bars of the sum "steric plus mass" time series are not shown for clarity. They are estimated to within $\pm 2 \mathrm{~mm}$ for individual monthly values. The mean trend over the study period (2005-2010) has been removed. The three GMSLs present similar variations and show reasonably good agreement with the sum of the components. Although small differences exist, the best agreement is found for the SL_cci GMSL. Correlation coefficients between the sum "steric plus mass" component and GMSL time series have also been computed. The highest correlation (of 0.65) is found with the SL_cci GMSL.

The results presented above are first attempts to validate the SL_cci products. We find some differences in terms of both global mean and regional variability with the standard products. Preliminary comparisons with the sum of the climate contributions (the sea level budget closure approach) suggest that the CCI product fits better the sum of the climatic components. However, this result is not robust considering the large uncertainties affecting the steric and mass components. Further work is needed on that matter, using different steric and ocean mass products with assessed uncertainties. For instance, the steric height from ocean reanalyses can also be used for global sea level budget closure (Balmaseda et al., 2013). This will be a topic for the CCI phase 2 activities.

\section{Error budget of sea level}

Although improvements were made, the SL_cci products still contain errors at different timescales. In order to inform users about these errors, we have established an error budget dedicated to the main spatio-temporal scales, i.e. global and regional, long-term (5-10 years or more), interannual $(<5$ years), and seasonal (see Table 2$)$ ). For each of these, an error was determined and compared to the sea level Climate User requirements (GCOS, 2011) which have been updated in the framework of the Sea Level CCI project (Sea Level CCI User Requirement Document - URD, 2013).

Regarding the GMSL trend, an uncertainty of $0.5 \mathrm{~mm}$ year $^{-1}$ was estimated over the whole altimetry era (1993-2010). This uncertainty is reduced by $0.1 \mathrm{~mm} \mathrm{year}^{-1}$ compared to the previous data based on AVISO-2010 

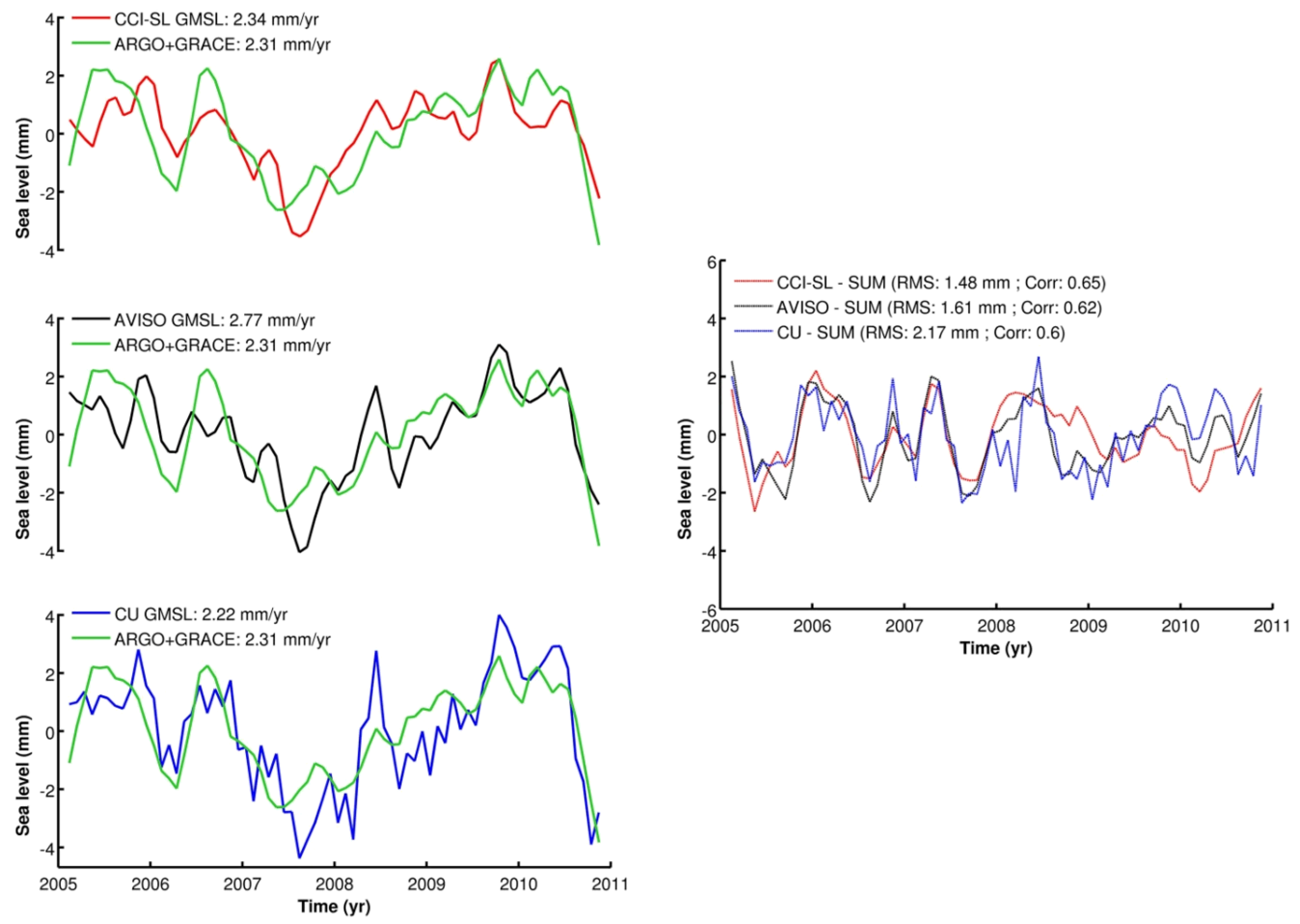

Figure 11. Sum of steric and ocean mass components based on Argo and Grace data (see Sect. 5.4) (green curve) over the January 2005December 2010 time period and different GMSL products (left panels). Right panel: difference between the GMSL products and sum of components.

Table 2. Error budget of SL_cci products for the main climate scales.

\begin{tabular}{|c|c|c|c|}
\hline Spatial scales & Temporal scales & Altimetry errors & User requirements \\
\hline \multirow[t]{2}{*}{ Global MSL } & $\begin{array}{l}\text { Long-term evolution } \\
\text { (>10 years) }\end{array}$ & $<0.5$ mm year $^{-1}$ & $0.3 \mathrm{~mm}$ year $^{-1}$ \\
\hline & Interannual signals $(<5$ years $)$ & $<2 \mathrm{~mm}$ over 1 year & $0.5 \mathrm{~mm}$ over 1 year \\
\hline \multirow[t]{2}{*}{ Regional MSL } & $\begin{array}{l}\text { Annual signals } \\
\text { Long-term evolution } \\
\text { (> } 10 \text { years) }\end{array}$ & $\begin{array}{l}<1 \mathrm{~mm} \\
<3 \text { mm year }^{-1}\end{array}$ & $\begin{array}{l}\text { Not defined } \\
1 \text { mm year }^{-1}\end{array}$ \\
\hline & Annual signals & $<1 \mathrm{~cm}$ & Not defined \\
\hline
\end{tabular}

standards over 1993-2008 (Ablain et al., 2009). While small, this reduction is mainly due to a 2 -year longer record as well as to the homogenization of the altimetry corrections between all the missions. The main source of the error remains the radiometer wet tropospheric correction with a drift uncertainty in the range of $0.2-0.3 \mathrm{~mm}_{\text {year }}{ }^{-1}$ (Legeais et al., 2014). To a lesser extent, the orbit error (Couhert et al., 2015) and the altimeter parameters (range, sigma-0, SWH) instabilities (Ablain et al., 2012) also add uncertainty, of the order of $0.1{\mathrm{~mm} y e a r^{-1}}^{-}$. Notice that for these two corrections, the uncertainties are higher in the first altimetry decade (1993-2002) where TOPEX/Poseidon, ERS-1 and ERS-2 measurements display stronger errors (Ablain et al.,
2013). Furthermore, imperfect links between TOPEX-A and TOPEX-B (February 1999), TOPEX-B and Jason-1 (April 2003), and Jason-1 and Jason-2 (October 2008) lead to the errors of $2 \mathrm{~mm}, 1 \mathrm{~mm}$ and $0.5 \mathrm{~mm}$ respectively (Ablain et al., 2009). They cause a GMSL trend error of about $0.15 \mathrm{~mm}$ year $^{-1}$ over the $1993-2010$ period. Although the SL_cci project work has led to significant improvements, the remaining uncertainty of $0.5 \mathrm{~mm}$ year $^{-1}$ on the GMSL trend remains $0.2 \mathrm{~mm}_{\text {year }}{ }^{-1}$ higher than the GCOS requirements (of $0.3 \mathrm{~mm}$ year $^{-1}$; see GCOS, 2011).

All sources of errors described above have also had an impact at the interannual timescale ( $<5$ years). Recent studies (Henry et al., 2013) have shown that the methodology ap- 
plied to calculate sea level is particularly sensitive for the interannual scales (Henry et al., 2014). We estimated that the methodology uncertainty is on average $\sim 2 \mathrm{~mm}$ over a 1-year period. Although improvements have been made, this level of error is still $1.5 \mathrm{~mm}$ higher than the GCOS requirement of $(0.5 \mathrm{~mm})$. This may have consequences on the sea level closure budget studies at the interannual timescale. For the annual signal, the amplitude error was estimated to be $<1 \mathrm{~mm}$. Knowing that the annual amplitude of the GMSL is of the order of $9 \mathrm{~mm}$, we can consider this error to be low. Notice that no requirement has yet been defined by GCOS for the periodic signals (at global and regional scales).

At the regional scale, the regional trend uncertainty is of the order of $2-3 \mathrm{~mm}$ year $^{-1}$. Although the orbit error has been significantly reduced for this spatial scale, it remains the main source of the error (in the range of 1-2 mm year ${ }^{-1}$; Couhert et al., 2015) with large spatial patterns at hemispheric scale. The earth gravity field model errors explain an important part of these uncertainties (Rudenko et al., 2014). Furthermore, errors are higher in the first decade (19932002), where the earth gravity field models are less accurate due to the unavailability of the GRACE data before 2002 . Additional errors are still observed; for example, for the radiometer-based wet tropospheric correction in tropical areas, other atmospheric corrections in high latitudes, and highfrequency corrections in coastal areas. The combined errors give rise to an uncertainty of $0.5-1.5 \mathrm{~mm}_{\text {year }}{ }^{-1}$. Finally, the $2-3 \mathrm{~mm}_{\text {year }}{ }^{-1}$ uncertainty on regional sea level trends remains a significant error compared to the $1 \mathrm{~mm}$ year $^{-1}$ GCOS requirement, even if this project has led to a 0.5 to $1.5 \mathrm{~mm}$ year $^{-1}$ reduction (Fig. 6 ).

\section{Conclusions and perspectives}

Several groups (AVISO, University of Colorado, CSIRO, JPL (Jet Propulsion Laboratory), etc.) are currently processing satellite altimetry data to provide sea level products to user for climate applications. Within the SL_cci project, we have continued to improve the multi-mission sea level products over the altimetry era (1993-2010) through the development and computation of new corrections listed in Table 1. As far as possible, we have homogenized these corrections between all the missions in order to reduce the sources of discrepancies. Thanks to our formal validation protocol, we have been able to select the best corrections and algorithms applied in the sea level calculation. We have produced new sea level products and additional indicators over the 19932010 period. The SL_cci products exhibit improvements of different levels of importance for climate studies. Some of them are substantial, for instance for the estimation of the regional sea level trends, with an error reduction of $0.5-$ $1.5 \mathrm{~mm}$ year $^{-1}$ with large correlated spatial patterns. In parallel, the uncertainties of altimetry sea level have been better characterized and the sea level user requirements refined for climate applications.

The validation exercise has demonstrated that the existence of an additional good-quality sea level record has value in itself. Firstly, it clearly shows that the AVISO and SL_cci altimeter-derived sea level gridded products are robust (small uncertainty compared with the model error) and able to identify model improvements. Therefore they are a suitable data set to define metrics in the validation of ocean and climate models. SL_cci can be treated as an independent data set for verification. It has been used in the recent inter-comparison of ocean reanalyses ORAIP (Balmaseda et al., 2014; Hernandez et al., 2014). Preliminary results show that the SL_cci is closer to the ensemble mean of ocean reanalyses (a robust estimator) than its predecessor AVISO, and suggest that some ocean reanalyses that assimilate AVISO may over-fit the altimeter data. Model outputs using ocean assimilation techniques also provide independent sea level estimations that can be used to validate the SL_cci. Results obtained in the frame of the SL_cci project show that the low-frequency variability and trends of SL_cci agree better with ocean data assimilation estimators than with AVISO, especially in the Southern Ocean, the eastern Pacific, and coastal areas.

However, while a lot of improvements have been made, the user requirements are not yet reached. Remaining uncertainties are still 0.2 and $1-2$ mm year $^{-1}$ higher than the GCOS requirements for the GMSL trend and regional trends respectively. Similarly, the sea level error over a 1-year period is about $2 \mathrm{~mm}$ on average instead of the required $0.5 \mathrm{~mm}$. Therefore it is still necessary to continue to improve the sea level time series to better understand key scientific issues, as raised in the abstract. Several ways of making improvements have already been identified and will be implemented during phase 2 of SL_cci project (January 2014 to December 2016).

For example, we plan to extend the sea level time series beyond 2010 using the same sea level corrections. By the end of year 2014, the current CCI_SL release will be extended until 2013 (included). And each subsequent year, we will extend the time series by 1 year. Additional improvements will be implemented; in particular, new orbit solutions, use of new atmospheric reanalyses based on the ERAClim project (Dee, 2014), new ocean tides, new radiometerbased wet troposphere corrections with improved long-term stability, etc. Furthermore, several level-2 altimetry data reprocessing activities are already planned by space agencies (CNES, NASA, ESA) for Jason-1, TOPEX/Poseidon, Envisat, and ERS missions, allowing us to benefit from homogenized data for both instrumental parameters and geophysical corrections. In addition, we intend to account for new altimeter missions already in orbit (CryoSat-2, SARAL/Altika) or to be launched in the near future (Jason-3, Sentinel-3). They are all relevant to extending the sea level time series with the same level of accuracy, and to improving coastal and highlatitude areas, which are of great interest for climate studies. Dedicated analyses will be performed in the Arctic re- 
gion in order to improve sea level estimates near or under sea ice where no data are currently available. In parallel, we will continue to refine the user requirements, further developing the link with users and space agencies. This will include a quantification of the requirements for accuracy and longterm stability for climate-quality observations of sea level in the coastal zone, a key area for climate change. We also would like to refine the budget error with the new measurements and the new corrections. Lastly, to continuously answer user needs, we will produce by the end of 2016 a new, improved sea level time series covering the 1993-2015 period.

Acknowledgements. This work was performed in the framework of the ESA CCI program supported by ESA. It was also made possible thanks to the support of CNES for several years in altimetry data processing; in particular, thanks to the use of SSALTO/DUACS system developed in the framework of the SALP project (Service d'Altimétrie et de Localisation Précise). We would also like to thank all contributors to this project who have participated actively in the SL_cci project, with special recognition to S. Dinardo and B. M. Lucas in support of ESA, for their diligent reviewing of all the documents and data sets produced by the SL_cci team.

Edited by: A. Schiller

\section{References}

Ablain, M., Cazenave, A., Valladeau, G., and Guinehut, S.: A new assessment of the error budget of global mean sea level rate estimated by satellite altimetry over 1993-2008, Ocean Sci., 5, 193201, doi:10.5194/os-5-193-2009, 2009.

Ablain, M., Philipps, S., Urvoy, M., Tran, N., and Picot, N.: Detection of Long-Term Instabilities on Altimeter Backscattering Coefficient Thanks to Wind Speed Data Comparisons from Altimeters and Models, Mar. Geodesy, 35, 42-60, doi:10.1080/01490419.2012.718675, 2012.

Ablain, M., Ollivier, A., Philipps, S., and Picot, N.: Why altimetry errors at climate scales are larger in the first decade (1993-2002)?, OSTST Boulders, October 2013, available at: http://www.aviso.altimetry.fr/fileadmin/documents/OSTST/ 2013/posters/Ablain_AltimetryErrorAtClimateScales.pdf (last access: 20 June 2014), 2013.

Altamimi, Z., Collilieux, X., and Métivier, L.: ITRF2008: An improved solution of the International Terrestrial Reference Frame, J. Geodesy, 85, 457-473, doi:10.1007/s00190-011-0444-4, 2011.

Andersen, O. B.: The DTU10 Gravity field and Mean sea surface (2010) Second international symposium of the gravity field of the Earth (IGFS2), 20-22 September 2010, Fairbanks, Alaska: available at: http://www.space.dtu.dk/english/ /media/ Institutter/Space/English/scientific_data_and_models/global_ marine_gravity_field/dtu10.ashx (last access: 20 June 2014), 2010.

Balmaseda, M. A., Mogensen, K., and Weaver, A. T.: Evaluation of the ECMWF ocean reanalysis system ORAS4, Q. J. R. Meteorol. Soc., 139, 1132-1161, doi:10.1002/qj.2063, 2013.
Balmaseda, M. A., Hernandez, F., Storto, A., Palmer, M. D., Alves, O., Shi, L., Smith, G. C., Toyoda, T., Valdivieso, M., Barnier, B., Behringer, D., Boyer, T., Chang, Y-S., Chepurin, G. A., Ferry, N., Forget, G., Fujii, Y., Good, S., Guinehut, S., Haines, K., Ishikawa Y., Keeley, S., Köhl, A., Lee, T., Martin, M., Masina, S., Masuda, S., Meyssignac, B., Mogensen, K., Parent, L., Peterson, K. A., Tang, Y. M., Yin, Y., Vernieres, G., Wang, X., Waters, J., Wedd, R., Wang, O., Xue, Y., Chevallier, M., Lemieux, J.-F., Dupont, F., Kuragano, T., Kamachi, M., Awaji, T., Caltabiano, A., WilmerBecker, K., and Gaillard, F.: The Ocean Reanalyses Intercomparison Project (ORA-IP), J. Operational Oceanography, submitted, 2014.

Brown, S., Desai, S., Keihm, S., and Lu, W.: Microwave radiometer calibration on decadal time scales using on-earth brightness temperature references: application to the TOPEX Microwave radiometer, J. Atmos. Oceanic Technol., 26, 2579-2591, 2009.

Carrere, L., Faugère, Y., and Ablain, M.: Improvement of pressure derived corrections for altimetry using the ERA-Interim dataset, Ocean Sci. Discuss. in preparation, 2014.

Chambers, D. P. and Bonin, J. A.: Evaluation of Release-05 GRACE time-variable gravity coefficients over the ocean, Ocean Sci., 8, 859-868, doi:10.5194/os-8-859-2012, 2012.

Couhert, A., Cerri, L., Legeais, J.-F., Ablain, M., Zelensky, N. P., Haines, B. J., Lemoine, F. G., Bertiger, W. I., Desai, S. D., and Otten, M.: Towards the $1 \mathrm{~mm} / \mathrm{y}$ stability of the radial orbit error at regional scales, Adv. Space Res., 55, 2-23, doi:10.1016/j.asr.2014.06.041, 2015.

Dee, D. P.: ERA-CLIM: Final Publishable Summary Report, available at: http://www.google.fr/url? $\mathrm{sa}=\mathrm{t} \& \mathrm{rct}=\mathrm{j} \& \mathrm{q}=\&$ esrc $=\mathrm{s} \&$ source $=$ web $\& \mathrm{~cd}=1 \& \mathrm{ved}=$ 0CCMQFjAA\&url=httpAFFwww.era-clim.euFFR_ 20140228.pdf\&ei=ifKsVM6bLMuAUaSfhNAJ\&usg= AFQjCNHMvrEekOqszSUT_Jti_8n3oF1saw\&sig2= yGNIOLhN3NBThCwNsqAC1A\&bvm=bv.83134100, d.d24 (last access: 18 August 2014), 2014.

Dee, D. P., Uppala, S. M., Simmons, A. J., Berrisford, P., Poli, P., Kobayashi, S., Andrae, U., Balmaseda, M. A., Balsamo, G., Bauer, P., Bechtold, P., Beljaars, A. C. M., van de Berg, L., Bidlot, J., Bormann, N., Delsol, C., Dragani, R., Fuentes, M., Geer, A. J., Haimberger, L., Healy, S. B., Hersbach, H., Hólm, E. V., Isaksen, L., Kållberg, P., Köhler, M., Matricardi, M., McNally, A. P., Monge-Sanz, B. M., Morcrette, J.-J., Park, B.-K., Peubey, C., de Rosnay, P., Tavolato, C., Thépaut, J.-N., and Vitart, F.: The ERA-Interim reanalysis: configuration and performance of the data assimilation system, Q. J. R. Meteorol. Soc., 137, 553-597, doi:10.1002/qj.828, 2011

Dibarboure, G., Pujol, M.-I., Briol, F., Le Traon, P. Y., Larnicol, G., Picot, N., Mertz, F., and Ablain, M.: Jason-2 in DUACS: Updated System Description, First Tandem Results and Impact on Processing and Products, Mar. Geodesy, 34, 214-241, 2011.

Ducet, N., Le Traon, P. Y., and Reverdin, G.: Global high resolution mapping of ocean circulation from the combination of TOPEX/POSEIDON and ERS-1/2, J. Geophys. Res.-Ocean., 105, 19477-19498, 2000.

Fernandes, M. J., Lázaro, C., Nunes, A. L., Pires, N., Bastos, L., and Mendes, V. B.: GNSS-derived Path Delay: an approach to compute the wet tropospheric correction for coastal altimetry, IEEE Geosci. Remote Sens Lett., 7, 596-600, doi:10.1109/LGRS.2010.2042425, 2010. 
Fernandes, M. J., Lázaro, C., and Nunes, A. L.: Improved Wet Path Delays for all ESA and Reference altimetric missions, Remote Sens. Environ., in preparation, 2014.

Garcia, P. and Roca, M.: ISARD_ESA_L1B_ESL_CCN_PRO_064, issue 1.b, 15 November 2010, "On-board PTR processing analysis: MSL drift differences", 2010.

GCOS: Systematic Observation Requirements for Satellite-Based Data Products for Climate (2011 Update) - Supplemental details to the satellite-based component of the "Implementation Plan for the Global Observing System for Climate in Support of the UNFCCC (2010 Update)", GCOS-154, WMO, December 2011.

Henry, O., Ablain, M., Meyssignac, B., Cazenave, A., Masters, D., Nerem, S., and Garric, G.: Effect of the processing methodology on satellite altimetry-based global mean sea level rise over the Jason-1 operating period, J. Geodesy, 88, 351-361, doi:10.1007/s00190-013-0687-3, 2014.

Hernandez, F., Ferry, N., Balmaseda, M., Chang, Y.-S., Chepurin, G., Fujii, Y., Guinehut, S., Kohl, A., Martin, M., Meyssignac, B., Parent, L., Peterson, K. A., Storto, A., Toyoda, T., Valdivieso, M., Vernieres, G., Wang, O., Wang, X., Xue, Y., and Yin, Y.: Sea level intercomparison: Inital resutls, Clivar Exchanges, 64, 1821, 2014.

Kölh, A.: Evaluation of the GECCO2 Ocean Synthesis: Transports of Volume, Heat and Freshwater in the Atlantic, Q. J. Roy. Meteor. Soc., doi:10.1002/qj.2347, 2014.

Laxon, S. W., Giles, K. A., Ridout, A. L., Wingham, D. J., Willatt, R., Cullen, R., Kwok, R., Schweiger, A., Zhang, J., Haas, C., Hendricks, S., Krishfield, R., Kurtz, N., Farrell, S., and Davidson, M.: CryoSat-2 estimates of Arctic sea ice thickness and volume, Geophys. Res. Lett., 40, 732-737, doi:10.1002/grl.50193, 2013.

Legeais, J.-F., Ablain, M., and Thao, S.: Evaluation of wet troposphere path delays from atmospheric reanalyses and radiometers and their impact on the altimeter sea level, Ocean Sci., 10, 893905, doi:10.5194/os-10-893-2014, 2014.

Le Traon, P. Y., Faugère, Y., Hernandez, F., Dorandeu, J., Mertz, F., and Ablain, M.: Can we merge GEOSAT Follow-On with TOPEX/POSEIDON and ERS-2 for an improved description of the ocean circulation?, J. Atmos. Ocean. Technol., 20, 889-895, 2003.

Morrison, H., Zuidema, P., Ackerman, A. S., Avramov, A., de Boer, G., Fan, J., Fridlind, A. M., Hashino, T., Harrington, J. Y., Luo, Y., Ovchinnikov, M., and Shipway, B.: Intercomparison of cloud model simulations of Arctic mixed-phase boundary layer clouds observed during SHEBA/FIRE-ACE, J. Adv. Model. Earth Syst., 3, M06003, doi:10.1029/2011MS000066, 2011.

Ollivier, A., Faugère, Y., Picot, N., Ablain, M., Femenias, P., and Benveniste, J.: Envisat Ocean Altimeter Becoming Relevant for Mean Sea Level Trend Studies, Mar. Geodesy, 35, 118-136, 2012.

Philipps, S. and Roinard, H.: Jason-2 reprocessing impact on ocean data (cycles 001 to 145), available at: http://www.aviso.altimetry.fr/fileadmin/documents/calval/ validation_report/J2/Jason2ReprocessingReport-v2.1.pdf (last access: 20 June 2014), 2013.

Pujol, M. I., Faugère, Y., Ablain, M., Larnicol, G., Picot, N., and Bronner, E.: 20 years of High Resolution DUACS/Aviso Products Reprocessed, Mar. Geodesy, in preparation, 2014.
Ray, R. D.: Precise comparisons of bottom-pressure and altimetric ocean tides, J. Geophys. Res.-Ocean., 118, 4570-4584, doi:10.1002/jgrc.20336, 2013.

Roca, M. and Thibaut, P.: ISARD_CLS_SALP_PTR_TN_042, Issue 1.a, 19 November 2009, "PTR study(3) -SALP Project- ", 2009.

Rudenko, S., Otten, M., Visser, P., Scharroo, R., Schöne, T., and Esselborn, S.: New improved orbit solutions for the ERS-1 and ERS-2 satellites, Adv. Space Res., 49, 1229-1244, 2012.

Rudenko, S., Dettmering, D., Esselborn, S., Schöne, T., Förste, Ch., Lemoine, J.-M., Ablain, M., Alexandre, D., and Neumayer, K.-H.: Influence of time variable geopotential models on precise orbits of altimetry satellites, global and regional mean sea level trends, Adv. Space Res., 54, 92-118, doi:10.1016/j.asr.2014.03.010, 2014.

Scharroo, R. and Smith, W. H. F.: A global positioning system based climatology for the total electron content in the ionosphere, J. Geophys. Res., 115, A10318, doi:10.1029/2009JA014719, 2010.

SL_cci Product Validation Plan (PVP): available at: http://www. esa-sealevel-cci.org/webfm_send/101, last access: 20 June 2014.

SL_cci Product Specification Document (PSD): available at: http://www.esa-sealevel-cci.org/webfm_send/229, last access: 20 June 2014.

SL_cci Product User Guide (PUG): available at: http://www. esa-sealevel-cci.org/webfm_send/212, last access: 20 June 2014

SL_cci User Requirement Document (URD): available at: http://www.esa-sealevel-cci.org/webfm_send/235, last access: 20 June 2014.

SL_cci Product Validation Internal Report (PVIR): available at: http://www.esa-sealevel-cci.org/webfm_send/234, last access: 20 June 2014.

SL_cci Validation Report: Executive Summary available at: http://www.esa-sealevel-cci.org/webfm_send/187, last access: 20 June 2014.

SL_cci Validation Report: Instrumental Corrections, available at: http://www.esa-sealevel-cci.org/webfm_send/175, last access: 20 June 2014.

SL_cci Validation Report: Orbit Calculation, available at: http://www.esa-sealevel-cci.org/webfm_send/176, last access: 20 June 2014.

SL_cci Validation Report: Wet Troposphere Correction, available at: http://www.esa-sealevel-cci.org/webfm_send/177, last access: 20 June 2014.

SL_cci Validation Report: Atmospherical corrections (Dynamical, Atmospherical correction, Inverse Barometer, Dry Troposphere) available at: http://www.esa-sealevel-cci.org/webfm_send/181, last access: 20 June 2014.

SL_cci Validation Report: Ionosphere correction, available at: http://www.esa-sealevel-cci.org/webfm_send/178, last access: 20 June 2014.

SL_cci Validation Report: Sea State Bias correction, available at: http://www.esa-sealevel-cci.org/webfm_send/179, last access: 20 June 2014.

SL_cci Validation Report: Ocean tides correction, available at: http://www.esa-sealevel-cci.org/webfm_send/180, last access: 20 June 2014.

SL_cci Validation Report: Regional SSH bias corrections between altimetry missions, available at: http://www.esa-sealevel-cci.org/ webfm_send/182, last access: 20 June 2014. 
SL_cci Validation Report: Impact of altimeter satellite constellation, available at: http://www.esa-sealevel-cci.org/webfm_send/ 183, last access: 20 June 2014.

SL_cci Validation Report: Mapping Methods, available at: http://www.esa-sealevel-cci.org/webfm_send/184, last access: 20 June 2014.

SL_cci Validation Report: High latitudes areas, available at: http://www.esa-sealevel-cci.org/webfm_send/185, last access: 20 June 2014.

SL_cci Validation Report: Coastal areas, available at: http://www.esa-sealevel-cci.org/webfm_send/186, last access: 20 June 2014.
Thao, S., Eymard, L., Obligis, E., and Picard, B.: Trend and Variability of the Atmospheric Water Vapor: a Mean Sea Level issue, J. Atmos. Ocean. Technol., 31 1881-1901, 2014.

Thibaut, P.: PTR position and drift analysis - Theoretical Approach”, RA-2 Quality Working Group presentation, Reading, UK, May 2010.

Valladeau, G., Legeais, J. F., Ablain, M., Guinehut, S., and Picot, N.: Comparing Altimetry with Tide Gauges and Argo Profiling Floats for Data Quality Assessment and Mean Sea Level Studies, Mar. Geodesy, 35, 42-60, 2012.

von Schuckmann, K. and Le Traon, P.-Y.: How well can we derive Global Ocean Indicators from Argo data?, Ocean Sci., 7, 783791, doi:10.5194/os-7-783-2011, 2011. 